\title{
ANÁLISE DA REPERCUSSÃO GERAL APÓS 10 ANOS DE APLICAÇÃO: AVANÇOS, DESAFIOS E DIAGNÓSTICO EM NÚMEROS
}

\author{
ANALYSIS OF THE GENERAL REPERCUSSION AFTER 10 YEARS OF APPLICATION:
}

\author{
ADVANCES, CHALLENGES AND DIAGNOSIS IN NUMBERS
}

\section{Anderson Orestes Cavalcante Lobato ${ }^{1}$ \\ Rodrigo Meireles Ortiz ${ }^{2}$}

\begin{abstract}
RESUMO
O trabalho pretende analisar alguns dos impactos proporcionados pela repercussão geral em dez anos de aplicação. Nesse intuito, aborda-se o processo de objetivação do controle de constitucionalidade da Leis no Brasil como origem da repercussão geral, para após se identificar os avanços proporcionados pelo instituto e os desafios a serem superados. Ademais, a partir dos dados coletados no site do Supremo Tribunal Federal até 08/04/2017, pretende-se verificar a repercussão geral em números, diagnosticando-se o tempo médio de julgamento para fixação de teses, os temas mais abordados, o tempo de julgamento por tema e a média de teses fixadas por mês. A pesquisa indica que o instituto detém propriedades virtuosas desde que adequadamente utilizadas. Ademais, os dados até então coletados apontam para alguns dos obstáculos a serem enfrentados diante do seu atual desempenho, como a necessidade do aumento do número de julgamentos que enfrentem o mérito da repercussão geral.
\end{abstract}

PALAVRAS-CHAVE: Repercussão Geral; Recurso Extraordinário; Jurisdição Constitucional; Controle de Constitucionalidade.

\section{ABSTRACT}

The paper intends to analyze some of the impacts provided by the general repercussion in ten years of application. For this, the process of objectifying the constitutionality control of Laws in Brazil is approached as the origin of the general repercussion, for after identify the advances provided by the institute and the challenges to be overcome. In addition, from the data collected on the website of the Federal Supreme Court until 08/04/2017, it is intended to verify the general repercussion in numbers, diagnosing the average time of judgment for the fixation of theses, the most approached themes, the time of judgment by theme and the

\footnotetext{
${ }^{1}$ Doutor em Direito Público pela Universidade de Toulouse/França. Professor da Universidade Federal do Rio Grande. Cidade do Rio Grande, Rio Grande do Sul, Brasil. E-mail: alobato@furg.br

2 Mestrando em Direito e Justiça Social pela Universidade Federal do Rio Grande. Cidade do Rio Grande, Rio Grande do Sul, Brasil. E-mail: rodrigo_ortiz@hotmail.com.br
} 
LOBATO, Anderson Orestes Cavalcante; ORTIZ, Rodrigo Meireles. Análise da Repercussão Geral após 10 anos de aplicação: avanços, desafios e diagnóstico em números. Revista Eletrônica Direito e Política, Programa de Pós-Graduação Stricto Sensu em Ciência Jurídica da UNIVALI, Itajaí, v.14, n.2, $2^{\circ}$ quadrimestre de 2019. Disponível em: www.univali.br/direitoepolitica - ISSN 1980-7791

average of the theses fixed for month. The research indicates that the institute possesses virtuous properties since properly used. In addition, the data collected so far point to some of the obstacles to be faced in the face of its current performance, such as the need to increase the number of judgments that face the merits of general repercussions.

KEYWORDS: General Repercussion; Extraordinary Appeal; Constitutional Jurisdiction; Constitutionality Control.

\section{INTRODUÇÃO}

O Poder Constituinte de 1988, preocupado com o desenvolvimento adequado das funções do Supremo Tribunal Federal frente ao aumento do contencioso constitucional, optou por fortalecer o controle abstrato e concentrado de constitucionalidade. Assim, criou a inconstitucionalidade por omissão, e ampliou o número de legitimados a propor as ações diretas perante o STF. Além disso, atribuiu eficácia erga omnes às decisões, vinculando a todos e resolvendo a questão de inconstitucionalidade uma única vez, no intuito de evitar a multiplicação de processos idênticos perante o Supremo. Entretanto, a medida não surtiu o efeito desejado. O número de recursos extraordinários não cedeu e o número de ações de controle concentrado não parou de crescer.

Este contexto adverso, o qual demonstrava a sobrecarga de trabalho e o crescimento contínuo do protocolo de processos no Supremo Tribunal Federal, aliado às severas críticas acerca da morosidade da justiça e o anseio social pela celeridade e previsibilidade das decisões judiciais, fez o Poder Constituinte Reformador, por meio da Emenda Constitucional no 45/2004, entre outras medidas, como a súmula vinculante, adotar um processo de objetivação do controle de constitucionalidade difuso, o que culminou com a criação da repercussão geral.

Após sua regulamentação, a qual entrou em vigência em 3 de maio de 2007, por meio da Emenda Regimental no 21/2007 ao Regimento Interno do Supremo Tribunal Federal, RISTF, a repercussão geral completou, em 2017, 10 anos de aplicação, mostrando-se conveniente um balanço de seus impactos e da sua eficácia formal. Assim, o presente estudo pretende analisar alguns dos impactos 
LOBATO, Anderson Orestes Cavalcante; ORTIZ, Rodrigo Meireles. Análise da Repercussão Geral após 10 anos de aplicação: avanços, desafios e diagnóstico em números. Revista Eletrônica Direito e Política, Programa de Pós-Graduação Stricto Sensu em Ciência Jurídica da UNIVALI, Itajaí, v.14, n.2, $2^{\circ}$ quadrimestre de 2019. Disponível em: www.univali.br/direitoepolitica - ISSN 1980-7791

proporcionados pela utilização da repercussão geral em dez anos de aplicação, adotando-se como hipótese o fato de que o instituto detém propriedades virtuosas, desde que adequadamente utilizado.

Com este intuito, o trabalho foi dividido em dois tópicos. No primeiro abordar-seá o processo de objetivação do controle difuso de constitucionalidade, realizandose uma breve análise da evolução do sistema até a criação do instituto da Repercussão Geral. Ademais, serão abordados os avanços que o instituto proporcionou, onde se destaca a contenção do número de processos distribuídos no Supremo, bem como a previsibilidade das decisões judiciais com a uniformização da interpretação constitucional. Após, retrata-se os desafios do instrumento, com ênfase no descompasso entre a maior admissão de processos sob a sistemática da repercussão geral e o julgamento de mérito de seus temas, bem como a necessária filtragem dos temas para apreciação.

No segundo tópico, analisa-se a eficácia formal do instituto da Repercussão Geral em números, a partir dos dados obtidos do site do STF até o dia 08/04/2017, os quais demonstram a abordagem de 961 temas e a fixação de 320 teses a serem aplicadas em casos idênticos por todos os juízes do País. Com base nestes dados, adotando como fundamento dois dos principais objetivos do instituto da repercussão geral, quais sejam, a diminuição de recursos no Supremo e o incremento na celeridade do julgamento, a pesquisa aborda cinco variáveis: o tempo médio de julgamento para fixação de teses; os temas mais abordados nos julgamentos; os temas mais abordados na totalidade de recursos no Supremo; o tempo de julgamento por tema abordado; a média de teses fixadas por ano e meses.

Dessa forma, além dos objetivos acima propostos, sustentada, sobretudo, no diagnóstico numérico da repercussão geral, a pesquisa visa a obtenção de elementos que permitam a reflexão do tema, orientem a tomada de decisões políticas sobre o assunto e permitam o aprimoramento da forma de aplicação do instituto. 
LOBATO, Anderson Orestes Cavalcante; ORTIZ, Rodrigo Meireles. Análise da Repercussão Geral após 10 anos de aplicação: avanços, desafios e diagnóstico em números. Revista Eletrônica Direito e Política, Programa de Pós-Graduação Stricto Sensu em Ciência Jurídica da UNIVALI, Itajaí, v.14, n.2, $2^{\circ}$ quadrimestre de 2019. Disponível em: www.univali.br/direitoepolitica - ISSN 1980-7791

\section{O PROCESSO DE OBJETIVAÇÃo DO CONTROLE DE CONSTITUCIONALIDADE DAS LEIS NO BRASIL}

Antes da Emenda Constitucional no 45/2004, na tentativa de limitar o número de processos e permitir uma análise adequada dos casos submetidos aos Ministros do Supremo Tribunal Federal, verificava-se uma jurisprudência conservadora da Suprema Corte, estabelecendo-se critérios rígidos para a admissibilidade e conhecimento do recurso extraordinário.

Ao lado disso, exigia-se motivação significativa para a admissão do Recurso Extraordinário, aprimorava-se a utilização das súmulas do Tribunal para julgamento monocrático e, posteriormente, criava-se no Regimento do STF, por meio da Emenda nº 03/1975, a Arguição de Relevância de Questão Federal.

O Constituinte de 1988 optou por fortalecer o controle abstrato e concentrado de constitucionalidade, criando a inconstitucionalidade por omissão e ampliando o número de legitimados a propor a ação direta, bem como atribuindo a esta a produção de efeitos erga omnes, independente do caso concreto, vinculando a todos e resolvendo a questão de inconstitucionalidade uma única vez, o que permitiria evitar a multiplicação de processos idênticos perante o STF. Entretanto, a medida não surtiu o efeito desejado. 0 número de recursos extraordinários não cedeu e o número de ações de controle concentrado não parou de crescer $^{3}$.

No âmbito infraconstitucional, buscando responder à demanda e conter o número de processos, o legislador ordinário, por meio da Lei no 8.038/1990 permitiu ao relator do recurso deixar de admitir o recurso extraordinário se a matéria já estivesse pacificada pelo Supremo Tribunal. Além disso, a Lei no 9.756/1998 passou a facultar o julgamento monocrático em situações consolidadas pela Suprema Corte.

Ocorre que as tentativas produziam nos jurisdicionados, muitas vezes, um sentimento de complexidade, frustração e injustiça, diante da incerteza do

3 LOBATO, Anderson Orestes Cavalcante. Política, Constituição e Justiça: os desafios para a consolidação das instituições democráticas. Revista de Sociologia e Política. Curitiba, no 17 , 2001 , p. 50. 
LOBATO, Anderson Orestes Cavalcante; ORTIZ, Rodrigo Meireles. Análise da Repercussão Geral após 10 anos de aplicação: avanços, desafios e diagnóstico em números. Revista Eletrônica Direito e Política, Programa de Pós-Graduação Stricto Sensu em Ciência Jurídica da UNIVALI, Itajaí, v.14, n.2, $2^{\circ}$ quadrimestre de 2019. Disponível em: www.univali.br/direitoepolitica - ISSN 1980-7791

conhecimento e análise do seu pedido. Ademais, frente à ausência de uma eficácia ampla das suas decisões prolatadas nos Recursos Extraordinários, o STF, de forma não razoável, era obrigado a analisar novamente milhares de idênticas demandas.

Nesse contexto adverso, o qual demonstrava a sobrecarga de trabalho e o crescimento contínuo do protocolo de processos no Supremo Tribunal Federal, aliados às severas críticas acerca da morosidade da justiça e ao anseio social pela celeridade e previsibilidade das decisões judiciais, buscou-se criar, no âmbito do controle difuso, um requisito de admissibilidade não apenas formal, mas que facultasse ao Supremo Tribunal Federal selecionar e analisar questões significantes para a ordem constitucional, com relevância social, política, econômica ou jurídica que transcendessem os interesses subjetivos das partes.

O intuito era o de permitir a análise da tese jurídica uma única vez, dispensando os Ministros de se pronunciar reiteradas vezes nos processos de matéria idêntica. Ademais, tentava-se prestigiar a Corte não como tribunal de recurso, mas sim, como guardiã da Constituição.

A opção do Constituinte foi tentar atribuir um caráter mais objetivo ao Recurso Extraordinário. Para tanto, criou-se o instrumento da repercussão geral, o qual permitiria a uniformização da jurisprudência constitucional sobre determinados assuntos por meio do controle difuso, selecionando controvérsias mais significativas para o debate e atribuindo efeito multiplicador às decisões da Suprema Corte. Assim, o novo modelo "deixa de ter caráter marcadamente subjetivo ou de defesa de interesse das partes, para assumir, de forma decisiva, a função de defesa da ordem constitucional objetiva"4.

Cabe frisar que ao lado da objetivação do Recurso Extraordinário, trazida pela Repercussão Geral, outra tentativa de mudança na jurisdição constitucional do país nasceu no seio do próprio Supremo, por meio da defesa da transcendência dos motivos determinantes da sentença (ratio decidendi) para o controle difuso, a qual

\footnotetext{
4 MENDES, Gilmar Ferreira. O sistema brasileiro de controle de constitucionalidade. In: Tratado de direito constitucional. Coordenado por: MARTINS, Ives Gandra da Silva; MENDES, Gilmar Ferreira; NASCIMENTO, Carlos Valder do. V. 1. 2a ed. E-book. São Paulo: Saraiva, 2012, p. 324.
} 
LOBATO, Anderson Orestes Cavalcante; ORTIZ, Rodrigo Meireles. Análise da Repercussão Geral após 10 anos de aplicação: avanços, desafios e diagnóstico em números. Revista Eletrônica Direito e Política, Programa de Pós-Graduação Stricto Sensu em Ciência Jurídica da UNIVALI, Itajaí, v.14, n.2, $2^{\circ}$ quadrimestre de 2019. Disponível em: www.univali.br/direitoepolitica - ISSN 1980-7791

não restou acolhida pela Suprema Corte, conforme consignado na Reclamação no 4335.

Após a inclusão da Repercussão Geral em 2004 no §30, art. 102, da Constituição Federal, sua regulamentação veio por meio da Lei no 11.418/06, de 19/12/06, a qual inseriu os artigos 543-A e 543-B ao antigo Código de Processo Civil, entrando em vigor sessenta dias após sua vigência, ou seja, em 19/02/07. Em razão disso, sobrevieram as Emendas ao Regimento Interno do Supremo Tribunal Federal de números 21, 22, 23, 24, 27, 31, 41, 42, 47 e 49, sendo a primeira datada em 30/04/2007 e publicada em 03/05/2007. Atualmente, o tema se encontra abordado nos artigos 1.029 a 1.041 do Código de Processo Civil.

\section{A) O impacto positivo da repercussão geral na conflitualidade judicial}

No ponto, verifica-se que a Repercussão Geral, logo após a sua implementação, proporcionou uma contenção significante no número de processos, sobretudo diminuindo a distribuição dos recursos e aumentando o julgamento monocrático. Para melhor visualização, a tabela abaixo demonstra a evolução dos recursos na Suprema Corte, de 2006 até 23/03/17:

QUADRO I - Evolução dos Recursos na Suprema Corte
\begin{tabular}{|c|c|c|c|c|c|}
\hline Ano & Protocolados & Distribuídos & $\begin{array}{c}\text { Julgamentos } \\
\text { monocráticos }\end{array}$ & $\begin{array}{c}\text { Julgamentos } \\
\text { Colegiados }\end{array}$ & $\begin{array}{c}\text { Total de } \\
\text { julgados }\end{array}$ \\
\hline 2017 & 21.779 & 10.123 & 16.008 & 1.841 & 17.849 \\
\hline 2016 & 89.971 & 57.367 & 96.019 & 13.155 & 109.174 \\
\hline 2015 & 93.503 & 65.108 & 93.713 & 15.480 & 109.193 \\
\hline 2014 & 79.943 & 57.799 & 92.722 & 15.242 & 107.964 \\
\hline 2013 & 72.072 & 44.170 & 72.167 & 12.833 & 85.000 \\
\hline 2012 & 72.148 & 46.392 & 72.995 & 11.044 & 84039 \\
\hline 2011 & 64.018 & 38.019 & 81.687 & 12.025 & 93712 \\
\hline 2010 & 71.670 & 41.014 & 87.815 & 10.714 & 98529 \\
\hline 2009 & 84.369 & 42.729 & 74.313 & 15.042 & 89.355 \\
\hline 2008 & 100.781 & 66.873 & 85.608 & 18.629 & 104.237 \\
\hline 2007 & 119.324 & 112.938 & - & - & 159.522 \\
\hline 2006 & 127.535 & 116.216 & - & - & 110.284 \\
\hline
\end{tabular}

Fonte: Brasil. Supremo Tribunal Federal ${ }^{5}$

Com efeito, a partir da inclusão do instituto da Repercussão Geral no dia-dia da Suprema Corte, criado em 2006, regulado em 2007 e aplicado com mais ênfase em 2008, ocorreu uma diminuição significativa do número de processos

\footnotetext{
${ }^{5}$ BRASIL. Supremo Tribunal Federal. 2017. Disponível em: <http://portal.stf.jus.br/>.
} 
LOBATO, Anderson Orestes Cavalcante; ORTIZ, Rodrigo Meireles. Análise da Repercussão Geral após 10 anos de aplicação: avanços, desafios e diagnóstico em números. Revista Eletrônica Direito e Política, Programa de Pós-Graduação Stricto Sensu em Ciência Jurídica da UNIVALI, Itajaí, v.14, n.2, $2^{\circ}$ quadrimestre de 2019. Disponível em: www.univali.br/direitoepolitica - ISSN 1980-7791

protocolados. Ao lado do protocolo, constata-se a significância do instituto na distribuição dos processos, talvez a mudança mais significativa proporcionada pela repercussão geral. No ponto, nota-se que ao se comparar o número de processos entre 2006 e 2016, tem-se uma queda significativa na distribuição de 58.849 processos, ou seja, uma redução de 50,64\% na distribuição de recursos. Isto é, a distribuição de processos foi reduzida a mais do que a metade, não se podendo constatar uma tendência de crescimento diante de sua variabilidade nos dez anos.

Entre as razões para estes dados se encontra o incremento de atribuições da Presidência da Corte a partir do instituto. No ponto, permitiu-se a devolução de processos semelhantes pelo artigo 543-B do antigo Código de Processo Civil, pois já deveriam ter sido sobrestados na origem ou, desde logo, reconsiderados ou considerados prejudicados, em razão da sistemática da repercussão geral. Além disso, destacou-se a possibilidade da Presidência em verificar que, ao se tratar de temas repetitivos, os quais geravam milhares de processos, poder-se-ia distribuir apenas alguns recursos representativos da controvérsia, suspendendo-se os demais.

Outro fator positivo para esta redução consiste na aplicação do regime da repercussão geral sobre o agravo de instrumento da decisão que não admite o Recurso Extraordinário na instância de origem e que sobrecarregava a Corte, já que posterga o exame de admissibilidade do próprio recurso extraordinário para depois da análise da existência, ou não, da repercussão geral pelo STF. Consequentemente, essa atribuição da Presidência, a qual culminou na diminuição da distribuição dos recursos, desonerou não só os relatores, mas também a própria estrutura do Tribunal, já que a análise passou a ser realizada antes da distribuição dos feitos no STF.

Além da análise da distribuição, constata-se que o número de julgamentos monocráticos, com exceção dos anos de 2008 e 2009, superou o número de processos protocolados, o que consequentemente permite concluir que houve uma redução da quantidade de recursos em estoque.

Aqui também se constata outra contribuição da Repercussão Geral, já que o instituto, ao uniformizar a jurisprudência sobre determinado tema, fortalece a 
LOBATO, Anderson Orestes Cavalcante; ORTIZ, Rodrigo Meireles. Análise da Repercussão Geral após 10 anos de aplicação: avanços, desafios e diagnóstico em números. Revista Eletrônica Direito e Política, Programa de Pós-Graduação Stricto Sensu em Ciência Jurídica da UNIVALI, Itajaí, v.14, n.2, $2^{\circ}$ quadrimestre de 2019. Disponível em: www.univali.br/direitoepolitica - ISSN 1980-7791

segurança do Relator ao julgar monocraticamente matéria já submetida ao Plenário em controle difuso de constitucionalidade. Inclusive, esta possibilidade foi acolhida pelo novo Código de Processo Civil, permitindo o julgamento monocrático pelo Relator do recurso caso a decisão contrarie o entendimento fixado na Repercussão Geral (art. 932, IV, b e V, b, todos do CPC).

Além da significativa contenção na distribuição de processos e no fortalecimento do julgamento monocrático dos recursos, embora não seja objeto específico deste trabalho, convém destacar a importância do instituto na filtragem e uniformização da interpretação constitucional sobre os temas enfrentados.

De fato, diversas decisões abordaram temas até então indefinidos, que causavam uma multiplicação de processos nas instâncias ordinárias e insegurança jurídica diante de decisões e entendimentos conflitantes. Cita-se alguns exemplos de matérias então controvertidas, tais como desaposentação, poderes investigatórios do Ministério Público, multiparentalidade, a responsabilidade do Estado na morte de detento, sistema prisional e déficit de vagas, eficácia da homologação da transação penal, sigilo bancário e acesso às informações pela autoridade fiscal, ações afirmativas e progressividade fiscal.

Com efeito, o resultado desses julgamentos não apenas reduz a quantidade de processos a serem analisados pelo próprio Supremo, como também repercute nas decisões de todo o país, afastando a insegurança jurídica e a possibilidade de decisões contraditórias em casos idênticos, já que uniformiza a interpretação constitucional. Consequentemente, prestigia-se a segurança jurídica, a previsibilidade das decisões, a razoável duração do processo e, ao se facultar um melhor entendimento ao jurisdicionado, o exercício democrático do poder.

\section{B) Os desafios do STF em oferecer uma solução definitiva aos litígios}

Os números expostos no QUADRO I demonstram que a partir da inclusão do instituto da Repercussão Geral ocorreu uma diminuição significativa do número de processos protocolados. Entretanto, a atual tendência do protocolo é crescente. De fato, nota-se que após a sua inserção no Regimento Interno do STF em 2007 houve uma contínua diminuição de protocolos, até o ano de 2011. Após 2011, os 
LOBATO, Anderson Orestes Cavalcante; ORTIZ, Rodrigo Meireles. Análise da Repercussão Geral após 10 anos de aplicação: avanços, desafios e diagnóstico em números. Revista Eletrônica Direito e Política, Programa de Pós-Graduação Stricto Sensu em Ciência Jurídica da UNIVALI, Itajaí, v.14, n.2, $2^{\circ}$ quadrimestre de 2019. Disponível em: www.univali.br/direitoepolitica - ISSN 1980-7791

dados demonstram que, salvo nos anos de 2013 e 2016, há um crescimento gradual do número de processos protocolados.

Isso demonstra que, conquanto os números de protocolos mais atuais sejam inferiores aos números de processos protocolados em 2006, ou seja, antes da Repercussão Geral, a solução não resolveu definitivamente o problema, podendo, ao manter o mesmo ritmo, em médio prazo alcançar novamente o mesmo patamar existente antes do instituto, exigindo uma análise mais profunda de suas causas.

Outro desafio ainda presente é constatado no descompasso entre o número de temas admitidos com repercussão geral e o número de temas que tem seu mérito julgado. Note-se os números do STF que indicam a desproporção:

QUADRO II - Comparação entre submissão e julgamento de mérito até 07/06/17

\begin{tabular}{|c|c|c|}
\hline Ano & Submetidos à RG & Mérito Julgado \\
\hline 2017 & 18 & 40 \\
\hline 2016 & 58 & 37 \\
\hline 2015 & 89 & 44 \\
\hline 2014 & 103 & 60 \\
\hline 2013 & 77 & 46 \\
\hline 2012 & 102 & 12 \\
\hline 2011 & 162 & 38 \\
\hline 2010 & 116 & 24 \\
\hline 2009 & 88 & 25 \\
\hline 2008 & 121 & 26 \\
\hline 2007 & 17 & 0 \\
\hline Total & 951 & 352 \\
\hline
\end{tabular}

Fonte: Brasil. Supremo Tribunal Federal ${ }^{6}$

Cumpre diminuir do total de recursos submetidos à sistemática da repercussão geral, 317 recursos cuja repercussão geral foi negada. Ainda assim, os dados demonstram uma tendência de que o Supremo submeteu um número superior de processos à sistemática da repercussão geral do que efetivamente julgou. Tal fato acaba por indicar a tendência do crescimento da quantidade do passivo de questões com repercussão geral a serem definidas, o que pode refletir no aumento do tempo de apreciação dos recursos, cujo cenário atual será verificado na sequência deste trabalho.

Segundo o site do Supremo, estão suspensos, aguardando um posicionamento da Corte em razão da repercussão geral, 1.514.969 processos em todo o país (Brasil,

\footnotetext{
${ }^{6}$ BRASIL. Supremo Tribunal Federal. 2017. Disponível em: <http://portal.stf.jus.br/>.
} 
LOBATO, Anderson Orestes Cavalcante; ORTIZ, Rodrigo Meireles. Análise da Repercussão Geral após 10 anos de aplicação: avanços, desafios e diagnóstico em números. Revista Eletrônica Direito e Política, Programa de Pós-Graduação Stricto Sensu em Ciência Jurídica da UNIVALI, Itajaí, v.14, n.2, $2^{\circ}$ quadrimestre de 2019. Disponível em: www.univali.br/direitoepolitica - ISSN 1980-7791

2017). Conforme manifestação do Ilustre Ministro Luis Roberto Barroso, no ritmo atual, seriam necessários mais 12 (doze) anos para julgamento do estoque de repercussões gerais, em um cenário utópico onde não se reconheceria mais nenhuma repercussão geral nos próximos anos ${ }^{7}$.

Além de questões vinculadas ao acesso à justiça, uma das possíveis causas deste descompasso consiste na utilização do Plenário Virtual. O Plenário Virtual representa um instrumento para o reconhecimento da repercussão geral de forma eletrônica, previsto nos artigos 323, 323-A e 324 do RISTF. Por meio da ferramenta, o relator inclui o feito com manifestação pela existência ou inexistência de repercussão geral da controvérsia constitucional discutida. Os demais ministros podem votar nos próximos 20 dias, em qualquer hora do dia ou da noite e em qualquer dia da semana. O mecanismo consiste em um instrumento facilitador, já que permite, de forma eletrônica e sem maiores formalidades o reconhecimento da Repercussão Geral pelos Ministros, desafogando a pauta do Plenário físico.

Entretanto, em razão da sua facilidade e comodidade, o Plenário Virtual acabou aparentemente contribuindo para o reconhecimento de uma ampla gama de temas com repercussão geral, o que não foi acompanhado pela velocidade em seus julgamentos de forma presencial, refletindo no aguardo do julgamento de temas há muito reconhecido como de repercussão geral. Ou seja: o que se denota é que o plenário virtual facilitou o reconhecimento da repercussão geral, mas criou um descompasso entre este e o julgamento pelo Plenário físico.

Por outro lado, o significativo e aparentemente crescente número de processos em estoque também dispensa atenção à possibilidade da paralisação na admissão de novos temas. De fato, os números fazem surgir uma preocupação com o reconhecimento de repercussão geral para casos futuros, diante da possibilidade do retrocesso jurisprudencial formalista e conservador para a admissibilidade da

\footnotetext{
7 BARROSO, Luis Roberto. Reflexões sobre as competências e o funcionamento do Supremo Tribunal Federal. 2014, p. 9. Disponível em: <s.conjur.com.br/dl/palestra-ivnl-reflexoes-stf25ago2014.pdf>.
} 
LOBATO, Anderson Orestes Cavalcante; ORTIZ, Rodrigo Meireles. Análise da Repercussão Geral após 10 anos de aplicação: avanços, desafios e diagnóstico em números. Revista Eletrônica Direito e Política, Programa de Pós-Graduação Stricto Sensu em Ciência Jurídica da UNIVALI, Itajaí, v.14, n.2, $2^{\circ}$ quadrimestre de 2019. Disponível em: www.univali.br/direitoepolitica - ISSN 1980-7791

repercussão geral nos recursos, o que demonstra a relevância da escolha dos assuntos a serem discutidos sob o regime da repercussão geral com parcimônia.

Assim, observa-se a necessidade de se tentar equacionar esta desproporção, competindo ao Supremo enfrentar o desafio decorrente de um acréscimo significativo no número de decisões que enfrentem, no mérito, controvérsias constitucionais em que reconhecida a repercussão geral, bem como uma filtragem eficaz das matérias a serem submetidas ao instituto.

Note-se que até 08/04/2017 foram fixadas sob a égide da repercussão geral 320 teses, o que representa a média de 32 (trinta e duas) teses por ano, menos de 3 (três) teses por mês e menos de uma tese por semana, contrastando com a importância atribuída pelo Constituinte Derivado, e atualmente pelo legislador ordinário, ao instituto da repercussão geral.

E esse equacionamento não pode deixar de considerar o número de teses a serem acolhidas no futuro, sob pena de, como dito, bloquear a admissão de novas repercussões gerais e regredir-se à jurisprudência conservadora e formalista utilizada para o conhecimento dos recursos extraordinários antes da repercussão geral.

Um dos instrumentos que tentou harmonizar o problema foi o novo Código de Processo Civil, o qual, em sua redação original, incluiu no art. 1.035, §10, o prazo máximo de um ano para apreciação da Repercussão Geral, sob pena de reativação de todos os processos no país. Contudo, respectivo dispositivo foi revogado meses antes da entrada em vigor do novo CPC em março de 2016, por meio da Lei no $13.256 / 16$.

De qualquer sorte, reconhece-se, como dito, a importância em incrementar o número de julgamento de mérito de matérias com repercussão geral, bem como em aprimorar a filtragem de questões efetivamente constitucionais com repercussão geral. E ao lado disso, cumpre analisar os dados até então produzidos sob a sistemática da repercussão geral para eventualmente identificar, ainda que 
LOBATO, Anderson Orestes Cavalcante; ORTIZ, Rodrigo Meireles. Análise da Repercussão Geral após 10 anos de aplicação: avanços, desafios e diagnóstico em números. Revista Eletrônica Direito e Política, Programa de Pós-Graduação Stricto Sensu em Ciência Jurídica da UNIVALI, Itajaí, v.14, n.2, $2^{\circ}$ quadrimestre de 2019. Disponível em: www.univali.br/direitoepolitica - ISSN 1980-7791

parcialmente, o surgimento de novos desafios às tentativas de aclimatação do controle difuso à realidade constitucional brasileira ${ }^{8}$.

\section{DA REPERCUSSÃO GERAL EM NÚMEROS}

Buscando refletir de maneira formal sobre as decisões da Suprema Corte, coletouse os dados relativos aos processos de todas as teses fixadas em sede de Repercussão Geral. Destaca-se que estas teses são as que efetivamente apreciam o mérito, solucionam o litígio e reativam os processos sobrestados nas instâncias de origem.

\subsection{Da Metodologia}

Além de seu aprimoramento instrumental, verifica-se que foram desenvolvidas ferramentas de estatística da própria repercussão geral, disponibilizadas no site do Supremo Tribunal Federal pela Assessoria de Gestão Estratégica. No presente estudo, foram analisadas as tabelas relativas às teses de repercussão geral, as quais foram complementadas pela tabela de Temas de Repercussão Geral e pela pesquisa individual em cada processo utilizado como paradigma para a fixação da tese, utilizando-se os dados presentes no andamento processual.

Para realização dos cálculos foram considerados os anos e os meses decorridos. Os dias, já que fracionados, foram excluídos. Para os julgados em que ainda não houve o trânsito em julgado, foi considerado o dia da análise global de todos os julgados e da realização da média do tempo decorrido: 08/04/2017. Os recursos já julgados, com trânsito, e que posteriormente substituíram o recurso paradigma, foram calculados com base na data da substituição do paradigma, e não do seu trânsito em julgado, já que refletem a data de sua utilização como repercussão geral.

\footnotetext{
8 TAVARES, A. L. L. Aspects de l'acclimatation du judicial review au droit brésilien. Revue Internationale de Droit Comparé. Paris, v. 4, 1986, p. 1136.
} 
LOBATO, Anderson Orestes Cavalcante; ORTIZ, Rodrigo Meireles. Análise da Repercussão Geral após 10 anos de aplicação: avanços, desafios e diagnóstico em números. Revista Eletrônica Direito e Política, Programa de Pós-Graduação Stricto Sensu em Ciência Jurídica da UNIVALI, Itajaí, v.14, n.2, $2^{\circ}$ quadrimestre de 2019. Disponível em: www.univali.br/direitoepolitica - ISSN 1980-7791

Para a obtenção da média do tempo decorrido, com relação aos anos, foi feita a média aritmética simples, somando-se todos os anos e dividindo-se pelo número de julgados. Com relação aos meses, também foi feita a média aritmética simples, somando-se todos os anos e dividindo-se pelo número de julgados. Após dividiuse a média dos meses por 12, para se chegar ao total em anos e, na sequência, somou-se à média de anos já obtida. Do resultado, o número inteiro foi considerado como ano, e o número após a vírgula foi multiplicado por 12, para a obtenção da média em meses. Do total de meses encontrados apenas se utilizou o número inteiro obtido, desconsiderando-se os valores após a vírgula.

Foram selecionadas para a pesquisa 5 (cinco) variáveis: 2.2) o tempo médio de julgamento para fixação de teses; 2.3 ) os temas mais abordados nos julgamentos; 2.4) os temas mais abordados na totalidade de recursos no Supremo; 2.5 ) o tempo de julgamento por tema abordado; 2.6) a média de teses fixadas por ano e meses.

No ponto, adotou-se como base dois objetivos do instituto da repercussão geral, quais sejam, a diminuição de recursos no Supremo e o incremento na celeridade do julgamento. E tendo em vista a breve exposição acima lançada acerca do primeiro resultado, a análise aqui realizada deu ênfase ao segundo objetivo. A separação analítica em temas foi adotada não só pela forma de apresentação dos dados estatísticos apresentados pelo site do Supremo, os quais já revelam sua divisão em temas, como também no desiderato de se verificar eventuais tendências, gargalos, dificuldades ou facilidades no tratamento de diferentes assuntos nestes 10 anos.

Assim, no item 2.2 busca-se constatar a eficácia geral do instituto na redução do tempo de julgamento dos recursos, calculando-se o tempo médio decorrido para cada processo. Na sequência, o item 2.3 utiliza-se dos dados do próprio Supremo para apurar o número de teses fixadas para cada tema, buscando identificar eventual preferência de assuntos enfrentados pela Corte nestes 10 anos do instituto.

O item 2.3 acaba conduzindo ao item 2.4 , onde se tenta verificar a harmonia entre os números de processos com temas analisados em repercussão geral e o número geral de processos protocolados no Supremo, com os seus respectivos temas. No 
LOBATO, Anderson Orestes Cavalcante; ORTIZ, Rodrigo Meireles. Análise da Repercussão Geral após 10 anos de aplicação: avanços, desafios e diagnóstico em números. Revista Eletrônica Direito e Política, Programa de Pós-Graduação Stricto Sensu em Ciência Jurídica da UNIVALI, Itajaí, v.14, n.2, $2^{\circ}$ quadrimestre de 2019. Disponível em: www.univali.br/direitoepolitica - ISSN 1980-7791

item 2.5 passa-se a verificar o tempo de duração do julgamento para cada assunto abordado. No ponto, a pesquisa mantém a mesma lógica, com a separação dos processos em temas e a análise do tempo de julgamento para cada tema, no intuito de observar as tendências dos assuntos mais abordados em comparação ao respectivo tempo de duração de seus julgamentos. E por fim, no item 2.6 se aborda de forma sintética a média do número de teses fixadas a cada ano, bem como a cada mês, de forma a constatar o funcionamento do instituto em termos estatísticos.

\subsection{Do tempo de julgamento para a fixação de teses}

Ao se apreciar todas as teses até então fixadas, e os recursos que lhes deram origem, verificou-se que a média de duração entre a data do protocolo do recurso e o seu respectivo trânsito em julgado é de 3 anos e 11 meses de julgamento.

Destaca-se a verificação de que esta média foi reduzida significativamente após a adoção mais frequente pela Suprema Corte, sobretudo a partir do ano de 2013, da técnica de julgamento de "reafirmação de jurisprudência". Nestes casos, na mesma sessão de julgamento, foi reconhecida a repercussão geral e julgado o mérito, apenas confirmando a jurisprudência da Corte. E assim, reduziu-se significativamente o tempo de julgamento.

No ponto, frisa-se que por meio da Emenda Regimental no 42/2010 houve previsão no Regimento Interno, especificamente no art. 323-A do RI do STF, do julgamento de mérito por meio eletrônico destes processos em que, apenas, reafirma-se a jurisprudência. Tamanha a importância dessa tendência de julgamento, que já há no site destinado à Repercussão Geral informações apontando a respectiva proporção:

GRÁFICO I - Comparação entre novos temas e reafirmação da jurisprudência em 07/06/17 
LOBATO, Anderson Orestes Cavalcante; ORTIZ, Rodrigo Meireles. Análise da Repercussão Geral após 10 anos de aplicação: avanços, desafios e diagnóstico em números. Revista Eletrônica Direito e Política, Programa de Pós-Graduação Stricto Sensu em Ciência Jurídica da UNIVALI, Itajaí, v.14, n.2, $2^{\circ}$ quadrimestre de 2019. Disponível em: www.univali.br/direitoepolitica - ISSN 1980-7791

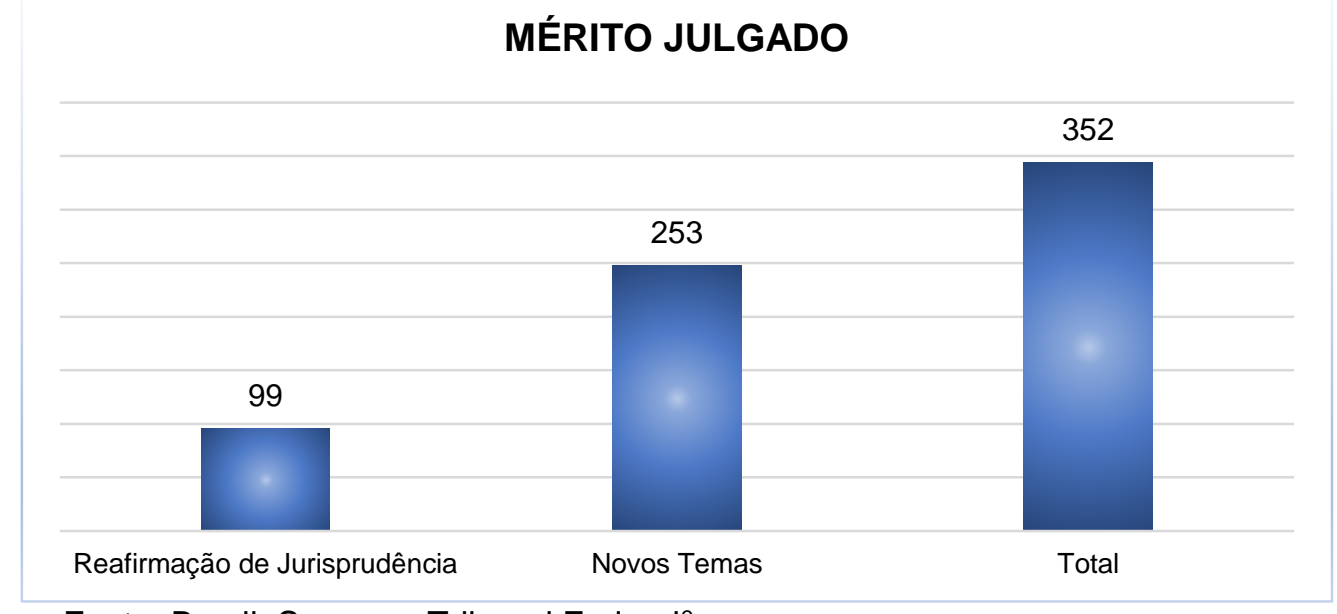

Fonte: Brasil. Supremo Tribunal Federal ${ }^{9}$

Em conclusão, considera-se que o tempo médio de decurso de 3 anos e 11 meses para o trânsito em julgado dos processos em que fixada repercussão geral é significativo para o julgamento do recurso. Sobretudo ao se considerar o tempo já transcorrido desde o início do trâmite do processo na instância originária e recursal, bem como a crescente utilização da reafirmação da jurisprudência, a qual não enfrenta temas novos e diminui expressivamente a média geral de decurso de tempo para a fixação de teses, já que na mesma sessão de julgamento, reconhece a repercussão geral e julga o mérito, confirmando a jurisprudência da Corte.

\subsection{Dos temas mais abordados nas decisões}

Buscando preservar a harmonia com o método estatístico divulgado nas tabelas do site do Supremo Tribunal Federal, manteve-se a análise dos temas segundo as tabelas fornecidas pelo próprio site do Supremo e que classificam as teses até então fixadas em 12 grupos: Direito Tributário, Direito Administrativo e outras matérias de Direito Público, Direito do Consumidor, Direito Processual Civil e do Trabalho, Direito Previdenciário, Direito Eleitoral e Processo Eleitoral, Direito Eleitoral, Direito Civil, Direito Processual Penal, Direito Processual Penal Militar, Direito Penal e Direito do Trabalho.

\footnotetext{
9 BRASIL. Supremo Tribunal Federal. 2017. Disponível em: <http://portal.stf.jus.br/>.
} 
LOBATO, Anderson Orestes Cavalcante; ORTIZ, Rodrigo Meireles. Análise da Repercussão Geral após 10 anos de aplicação: avanços, desafios e diagnóstico em números. Revista Eletrônica Direito e Política, Programa de Pós-Graduação Stricto Sensu em Ciência Jurídica da UNIVALI, Itajaí, v.14, n.2, $2^{\circ}$ quadrimestre de 2019. Disponível em: www.univali.br/direitoepolitica - ISSN 1980-7791

A análise permitiu verificar que, entre todas as teses fixadas, há uma preponderância dos julgados incluídos no grupo de Direito Administrativo e outras matérias de Direito Público. Observe-se:

GRÁFICO II - Números de teses por tema

\section{TESES COM RG}

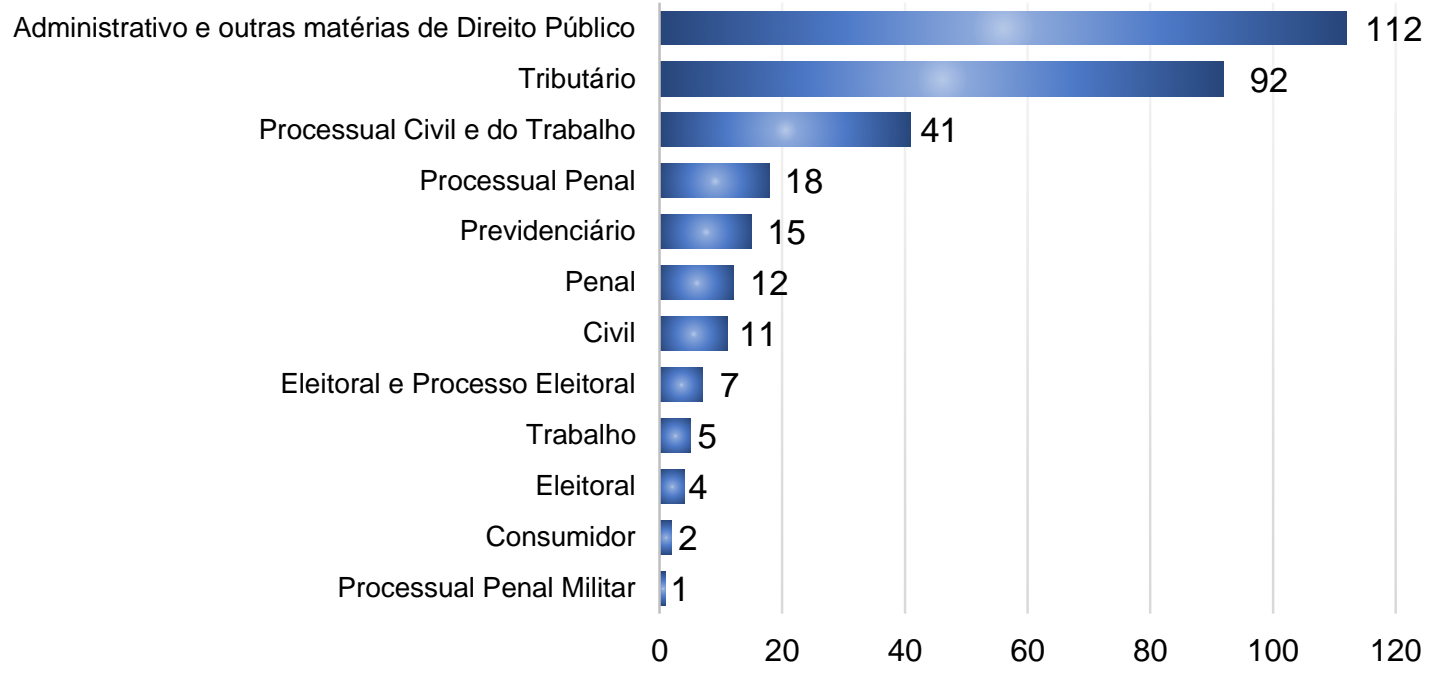

Fonte: Brasil. Supremo Tribunal Federal ${ }^{10}$

Note-se que ao se verificar que 92 teses estão no ramo de Direito Tributário e 112 no ramo residual de Direito Administrativo e outras matérias de Direito Público, há a presunção da tendência de que o maior número de teses está concentrado, de fato, no ramo de Direito Tributário. Isto pois, o grupo Direito Administrativo e outras matérias de Direito Público abrange uma ampla gama de assuntos, em caráter residual.

Outra constatação relevante consiste no fato de que os três primeiros grupos representam mais de $75 \%$ de todas as teses fixadas. Matérias privadas, como Civil e Consumidor, representam pouco menos de $5 \%$ do total de teses.

10 BRASIL. Supremo Tribunal Federal. 2017. Disponível em: <http://portal.stf.jus.br/>. 
LOBATO, Anderson Orestes Cavalcante; ORTIZ, Rodrigo Meireles. Análise da Repercussão Geral após 10 anos de aplicação: avanços, desafios e diagnóstico em números. Revista Eletrônica Direito e Política, Programa de Pós-Graduação Stricto Sensu em Ciência Jurídica da UNIVALI, Itajaí, v.14, n.2, $2^{\circ}$ quadrimestre de 2019. Disponível em: www.univali.br/direitoepolitica - ISSN 1980-7791

\subsection{Dos temas mais abordados na totalidade dos Recursos no Supremo}

Verificando o site do Supremo, constata-se que o Ramo do Direito que representa o maior número de recursos distribuídos, em harmonia com o maior número de teses, é o Direito Administrativo. Observe-se os dados no quadro abaixo:

QUADRO III - Número de Recursos por tema em 28/03/2017

\begin{tabular}{|c|c|c|}
\hline Ramo do Direito & Processos & $\%$ \\
\hline Administrativo e outras matérias de Direito Público & 92.089 & 34,59 \\
\hline Tributário & 35.485 & 13,33 \\
\hline Processual Civil e do Trabalho & 32.520 & 12,22 \\
\hline Civil & 28.577 & 10,73 \\
\hline Previdenciário & 25.950 & 9,75 \\
\hline Consumidor & 16.317 & 6,13 \\
\hline Trabalho & 15.284 & 5,74 \\
\hline Processual Penal & 10.857 & 4,08 \\
\hline Penal & 7.546 & 2,83 \\
\hline Eleitoral e Processo Eleitoral & 815 & 0,31 \\
\hline Eleitoral & 545 & 0,20 \\
\hline Direito da Criança e do Adolescente & 47 & 0,02 \\
\hline Registros Públicos & 98 & 0,04 \\
\hline Processual Penal Militar & 89 & 0,03 \\
\hline Total & 226.219 & 100 \\
\hline
\end{tabular}

Fonte: Brasil. Supremo Tribunal Federal ${ }^{11}$

Comparando-se estes dados aos processos em que houve fixação de teses, verifica-se que os três primeiros temas coincidem em termos de preponderância. Quanto aos demais temas, é possível identificar um pequeno descompasso no enfrentamento das matérias de direito privado, precisamente Direito Civil e Consumidor. Esta divergência é facilmente verificada ao se analisar o tema Direito do Consumidor. No ponto, há duas teses fixadas para o tema, o qual desponta no $11^{0}$ lugar nas teses, representando $0,62 \%$ do total. Em contraponto, Direito do Consumidor encontra-se no sexto lugar de todos os recursos protocolados no Supremo, representando $6,13 \%$ do total. Direito Civil se encontra no 70 lugar nas teses, representando $3,43 \%$ do total. Em contraste, no número total de recursos, Direito Civil está em 40 lugar, representando 10,73\% do total. Em porcentagens totais, na repercussão geral estes dois ramos representam $6,75 \%$ do total de teses, enquanto totalizam $16,86 \%$ quando considerados todos os recursos protocolados no Supremo.

11 BRASIL. Supremo Tribunal Federal. 2017. Disponível em: <http://portal.stf.jus.br/>. 
LOBATO, Anderson Orestes Cavalcante; ORTIZ, Rodrigo Meireles. Análise da Repercussão Geral após 10 anos de aplicação: avanços, desafios e diagnóstico em números. Revista Eletrônica Direito e Política, Programa de Pós-Graduação Stricto Sensu em Ciência Jurídica da UNIVALI, Itajaí, v.14, n.2, $2^{\circ}$ quadrimestre de 2019. Disponível em: www.univali.br/direitoepolitica - ISSN 1980-7791

Outra constatação significante é de que o número de recursos em Direito Administrativo representa mais de $1 / 3$ do total de recursos. Além disso, totaliza quase o triplo de processos envolvendo o segundo ramo de Direito Tributário. Considera-se que uma conclusão mais precisa sobre estes dados necessita da análise dos processos em que, embora reconhecida a repercussão geral, ainda não houve julgamento de mérito, o que deverá ser objeto de outro trabalho.

De qualquer sorte, por ora, acredita-se que os números denotam um enfrentamento menor de matérias de direito privado no âmbito da repercussão geral. Ademais, permite-se, por indução, considerar que a abordagem mais destacada dos recursos inseridos no atual ramo de Direito Administrativo e outras matérias de Direito Público irradiaria efeitos para um leque maior de processos, e presumidamente de litígios ainda pendentes, permitindo reduzir o número total de processos a aguardar uma decisão, já que representam mais de $1 / 3$ do total de recursos presentes no STF.

\subsection{Do cotejo entre os temas abordados e o tempo de julgamento}

Busca-se no presente tópico analisar o tempo de duração na análise de cada tema. A metodologia permanece a mesma, apenas limitando-se a análise da média do tempo de julgamento, aí considerado o protocolo do recurso e o seu trânsito em julgado, por cada tema, resultando no quadro e gráfico a seguir produzidos: 
LOBATO, Anderson Orestes Cavalcante; ORTIZ, Rodrigo Meireles. Análise da Repercussão Geral após 10 anos de aplicação: avanços, desafios e diagnóstico em números. Revista Eletrônica Direito e Política, Programa de Pós-Graduação Stricto Sensu em Ciência Jurídica da UNIVALI, Itajaí, v.14, n.2, $2^{\circ}$ quadrimestre de 2019. Disponível em: www.univali.br/direitoepolitica - ISSN 1980-7791

QUADRO IV - Tempo de duração por tema

\begin{tabular}{|c|c|c|c|c|}
\hline Tema & Números & Média & Anos & Meses \\
\hline Administrativo e outras matérias de Direito Público & 112 & 3,89 & 3 & 10 \\
\hline Tributário & 92 & 4,73 & 4 & 8 \\
\hline Processual Civil e do Trabalho & 41 & 3,12 & 3 & 1 \\
\hline Processual Penal & 18 & 3,87 & 3 & 10 \\
\hline Previdenciário & 15 & 2,75 & 2 & 9 \\
\hline Penal & 12 & 2,93 & 2 & 11 \\
\hline Civil & 11 & 4,59 & 4 & 7 \\
\hline Eleitoral e Processo Eleitoral & 7 & 2,89 & 2 & 10 \\
\hline Trabalho & 5 & 4,38 & 4 & 4 \\
\hline Eleitoral & 4 & 1,72 & 1 & 8 \\
\hline Consumidor & 2 & 4,75 & 4 & 9 \\
\hline Processual Penal Militar & 1 & 1,16 & 1 & 2 \\
\hline Internacional & 0 & 0 & 0 & 0 \\
\hline Total & 320 & 3,93 & 3 & 11 \\
\hline
\end{tabular}

Fonte: Brasil. Supremo Tribunal Federal ${ }^{12}$

GRÁFICO IV - Tempo de duração por tema

\section{Tempo de julgamento em anos}

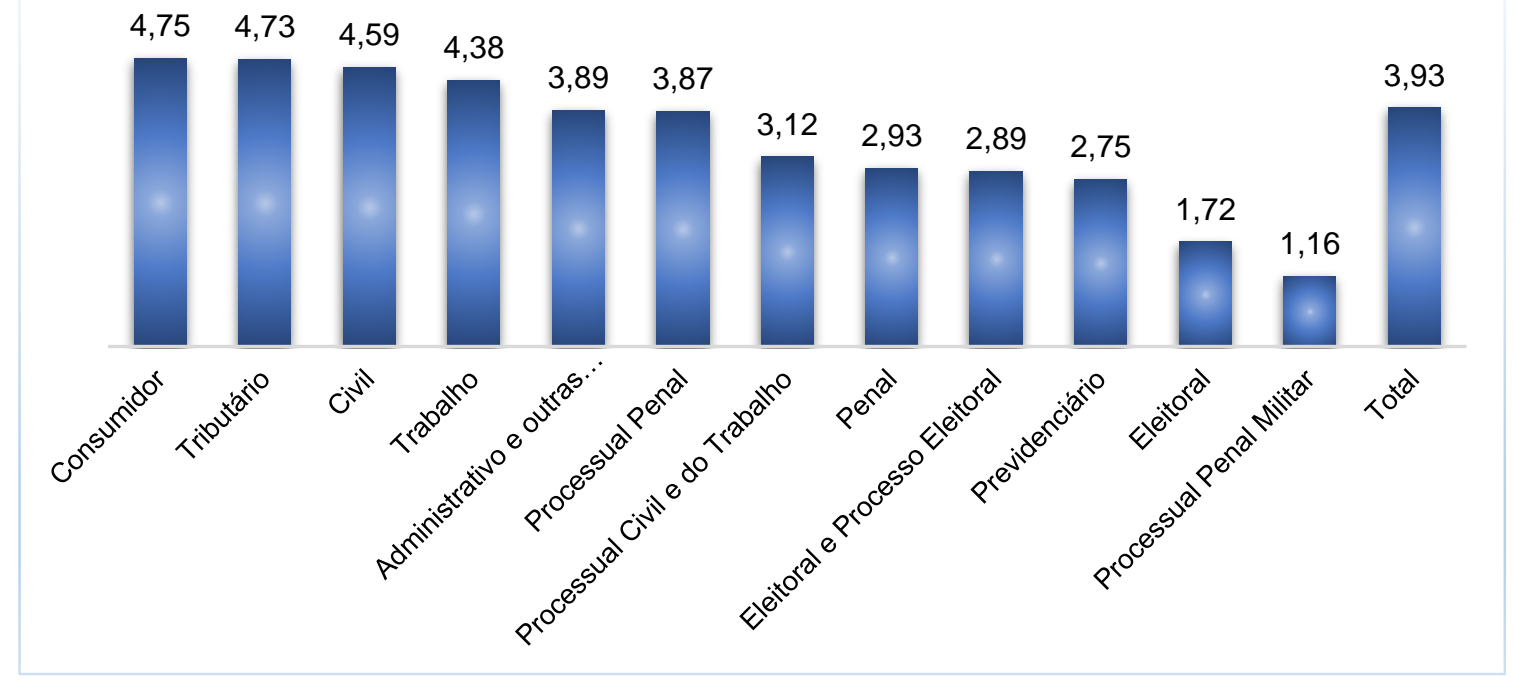

Fonte: BRASIL. Supremo Tribunal Federal ${ }^{13}$

Conforme se pode notar, o ramo que consome o maior intervalo de tempo consiste no Direito do Consumidor, seguido, logo atrás, pelo Direito Tributário. Cumpre frisar que o tema Direito do Consumidor possui apenas 2 teses, enquanto Direito Tributário 92. Tal fato permite concluir, por indução, que a média de Direito Tributário é mais fidedigna, dada a base de cálculo mais ampla para a sua

12 BRASIL. Supremo Tribunal Federal. 2017. Disponível em: <http://portal.stf.jus.br/>.

13 BRASIL. Supremo Tribunal Federal. 2017. Disponível em: <http://portal.stf.jus.br/>. 
LOBATO, Anderson Orestes Cavalcante; ORTIZ, Rodrigo Meireles. Análise da Repercussão Geral após 10 anos de aplicação: avanços, desafios e diagnóstico em números. Revista Eletrônica Direito e Política, Programa de Pós-Graduação Stricto Sensu em Ciência Jurídica da UNIVALI, Itajaí, v.14, n.2, $2^{\circ}$ quadrimestre de 2019. Disponível em: www.univali.br/direitoepolitica - ISSN 1980-7791

obtenção. E consequentemente, tende a demonstrar a probabilidade de uma demora maior entre todos os temas analisados de Direito Tributário.

Na espécie, cotejando este dado com o número de teses fixadas, observa-se a prospecção de que o ramo que possui o segundo maior número de teses é aquele em que o prazo para julgamento é o segundo maior.

\subsection{Da média de teses fixadas por ano e por meses}

Destaca-se em tópico específico o número médio de teses fixadas no tempo. E no particular, constata-se que em 10 anos de aplicação foram fixadas 320 teses, o que resulta em uma média simples de 32 teses por ano. Dividindo-se este número por 12 , chegamos ao total de 2,66 teses fixadas por mês e menos de uma tese fixada por semana.

Considerando a sistemática da repercussão geral, a qual envolve a suspensão de milhares de processos em todo o país, o número de temas ainda afetados, bem como o objetivo do instituto em uniformizar a interpretação de questões significantes para a ordem constitucional, com relevância social, política, econômica ou jurídica que transcendessem os interesses subjetivos das partes, observa-se que o número médio de 2,66 teses mensais pode dificultar o atendimento ao fim do instituto e a sua plena eficácia.

\section{CONSIDERAÇÕES FINAIS}

No presente trabalho, buscou-se realizar um balanço da repercussão geral em seus 10 (dez) anos de aplicação, utilizando-se como base as informações disponíveis no site do Supremo Tribunal Federal. A análise do avanço proporcionado pelo instituto demonstrou a diminuição significativa no número de processos que são distribuídos, o fortalecimento do julgamento monocrático dos recursos, aliando-se à previsibilidade das decisões judiciais com a uniformização da interpretação constitucional. 
LOBATO, Anderson Orestes Cavalcante; ORTIZ, Rodrigo Meireles. Análise da Repercussão Geral após 10 anos de aplicação: avanços, desafios e diagnóstico em números. Revista Eletrônica Direito e Política, Programa de Pós-Graduação Stricto Sensu em Ciência Jurídica da UNIVALI, Itajaí, v.14, n.2, $2^{\circ}$ quadrimestre de 2019. Disponível em: www.univali.br/direitoepolitica - ISSN 1980-7791

Em contraponto, a investigação dos desafios permitiu identificar que há uma tendência de crescimento no protocolo de recursos, o que pode dificultar a eficácia do instituto em médio prazo. Ademais, constatou-se que há uma aparente admissão de processos sob a sistemática da repercussão geral superior ao julgamento de mérito de seus temas, demonstrando-se a existência de outro obstáculo a ser enfrentado.

A partir da coleta de dados do site do Supremo, onde foram analisados os processos em houve a fixação de tese pela sistemática da Repercussão Geral até 08/04/2017, observou-se, entre outros, que o tempo médio de julgamento dos recursos submetidos à sistemática da Repercussão Geral é de 3 anos e 11 meses; presumidamente, este intervalo seria significativamente superior caso não utilizada a técnica de reafirmação de jurisprudência; o tema com o maior número de teses fixadas pelo Supremo é de Direito Administrativo e outras matérias de Direito Público; entretanto, em razão da pequena diferença numérica com o tema segundo colocado de Direito Tributário, e do caráter residual do primeiro, denotase que os temas abordados, por presunção, são predominantemente fiscais; a comparação entre o tempo de julgamento e os temas abordados apontam à tendência para uma maior demora no julgamento das questões tributárias; a análise do número de processos ingressos no STF revela que a maioria dos recursos são localizados no tema de Direito Administrativo e outras matérias de Direito Público, representando quase $1 / 3$ do total de recursos presentes no Supremo; e a média mensal na fixação de teses é de 2,66 teses por mês.

Relembra-se que a eficácia da repercussão geral não afeta apenas a Suprema Corte, mas também os juízes de todo o país, os quais suspendem a tramitação de seus processos com teses idênticas e aguardam a uniformização da interpretação constitucional pelo STF, bem como os jurisdicionados, que esperam uma resposta célere ao seu pedido, denotando a importância do aprimoramento e otimização da aplicação do instituto para o alcance de seus fins. Os números ainda fazem surgir a preocupação com o reconhecimento da repercussão geral para casos futuros, diante do atual estoque e tendência de crescimento de processos, o que pode implicar em um entendimento jurisprudencial restritivo para a admissibilidade da repercussão geral nos recursos vindouros. 
LOBATO, Anderson Orestes Cavalcante; ORTIZ, Rodrigo Meireles. Análise da Repercussão Geral após 10 anos de aplicação: avanços, desafios e diagnóstico em números. Revista Eletrônica Direito e Política, Programa de Pós-Graduação Stricto Sensu em Ciência Jurídica da UNIVALI, Itajaí, v.14, n.2, $2^{\circ}$ quadrimestre de 2019. Disponível em: www.univali.br/direitoepolitica - ISSN 1980-7791

Assim, constata-se que o instituto da Repercussão Geral possui propriedades virtuosas, sendo que os dados até então coletados e referentes às teses fixadas apontam para os obstáculos a serem enfrentados diante da sua atual eficácia formal. De fato, em que pese tenha o trabalho se debruçado sobre o aspecto formal e estatístico do instituto, diante das informações coletadas, observa-se o desafio em se aumentar o número de julgamentos que enfrentem o mérito da repercussão geral e aplicar uma filtragem eficaz das matérias a serem submetidas ao instituto.

\section{REFERÊNCIA DAS FONTES CITADAS}

BARROSO, Luís Roberto. Constituição, Democracia e Supremacia Judicial: Direito e Política no Brasil Contemporâneo. Revista Jurídica da Presidência. Brasília, vo 12, no 96, 2008.

BARROSO, Luis Roberto. Reflexões sobre as competências e o funcionamento do Supremo Tribunal Federal. 2014. Disponível em: <s.conjur.com.br/dl/palestra-ivnl-reflexoes-stf-25ago2014.pdf>.

BRASIL. Supremo Tribunal Federal. 2017. Disponível em: <http://portal.stf.jus.br/>.

BURDEAU, G. L'État. Paris: Seuil. 1970.

CARVALHO FILHO, José dos Santos. Os impactos da repercussão geral do recurso extraordinário na jurisdição constitucional brasileira: promoção do acesso à justiça, redefinição de competências e consolidação do sistema eclético de controle de constitucionalidade. Dissertação (Mestrado em Constituição e Sociedade) - Instituto Brasiliense de Direito Público. Brasília, Distrito Federal. 2011.

LOBATO, Anderson Orestes Cavalcante. Para uma nova compreensão do sistema misto de controle de constitucionalidade: a aceitação do controle preventivo. Cadernos de Direito Constitucional e Ciência Política. São Paulo, v. 2, n. 6, jan-mar. 1994.

LOBATO, Anderson Orestes Cavalcante. Política, Constituição e Justiça: os desafios para a consolidação das instituições democráticas. Revista de Sociologia e Política. Curitiba, no 17, 2001.

MENDES, Gilmar Ferreira. O sistema brasileiro de controle de constitucionalidade. In: Tratado de direito constitucional. Coordenado por: MARTINS, Ives Gandra da Silva; MENDES, Gilmar Ferreira; NASCIMENTO, Carlos Valder do. v. 1. $2^{\mathrm{a}}$ ed. E-book. São Paulo: Saraiva, 2012, p. 309-385. 
LOBATO, Anderson Orestes Cavalcante; ORTIZ, Rodrigo Meireles. Análise da Repercussão Geral após 10 anos de aplicação: avanços, desafios e diagnóstico em números. Revista Eletrônica Direito e Política, Programa de Pós-Graduação Stricto Sensu em Ciência Jurídica da UNIVALI, Itajaí, v.14, n.2, $2^{\circ}$ quadrimestre de 2019. Disponível em: www.univali.br/direitoepolitica - ISSN 1980-7791

SOUZA NETO, Cláudio Pereira de; SARMENTO, Daniel. Direito constitucional: teoria, história e métodos de trabalho. $1^{\text {a }}$ Edição. E-pub. Belo Horizonte: Fórum, 2012.

TAVARES, A. L. L. Aspects de l'acclimatation du judicial review au droit brésilien. Revue Internationale de Droit Comparé. Paris, v. 4, 1986.

RECEBIDO EM: 01/02/2019

APROVADO EM: 16/07/2019 